\title{
Water Bird Communities in Nonoperational Cigu Salt Pan Wetland of Varying Land Elevation and Water Depth on the Southwest Taiwan Coast
}

\author{
Perng-Sheng Chen ${ }^{1,2}$, Shyh-Jeng Chyi', Tung-Hui Kuo ${ }^{3}$, \\ Po-Ling Deng4, Ching-Lung Liu ${ }^{4}$, Yih-Tsong Ueng4* \\ ${ }^{1}$ Department of Geography, National Kaohsiung Normal University, Taiwan \\ ${ }^{2}$ Marine National Park, Construction and Planning Agency, Ministry of the Interior, Taiwan \\ ${ }^{3}$ Wild Bird Society of Tainan, Taiwan \\ ${ }^{4}$ Department of Environmental Engineering, Kun-Shan University, Taiwan

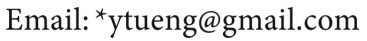

How to cite this paper: Chen, P.-S., Chyi, S.-J., Kuo, T.-H., Deng, P.-L., Liu, C.-L. and Ueng, Y.-T. (2020) Water Bird Communities in Nonoperational Cigu Salt Pan Wetland of Varying Land Elevation and Water Depth on the Southwest Taiwan Coast. Natural Resources, 11, 20-37.

https://doi.org/10.4236/nr.2020.111002

Received: December 5, 2019

Accepted: January 16, 2020

Published: January 19, 2020

Copyright $\odot 2020$ by author(s) and Scientific Research Publishing Inc. This work is licensed under the Creative Commons Attribution International License (CC BY 4.0).

http://creativecommons.org/licenses/by/4.0/

\begin{abstract}
The Black-faced Spoonbill (Platalea minor) is a critically endangered species. More than $50 \%$ of these spoonbills winter regularly on the southwestern coast of Taiwan. From 2007 to 2019, the rate of increase of the Black-faced Spoonbill population was only $10.5 \%$, which is lower than the rate of $12.0 \%$ per year reported between 1991 and 2004. Black-faced Spoonbills have experienced several bottlenecks, and problems may exist in their breeding and/or in wintering habitats. Understanding the ecological environment of their habitats in Taiwan is an important issue, including the current use of water birds, the water depth of their habitats and even the aquatic plants. A total population of 93,614 birds of 88 species was recorded in a survey of the Cigu salt pan from October 2017 to October 2018. The biodiversity $H^{\prime}$ (loge) of the total birds was 2.67. Dunlin (Calidris alpina) was the most dominant species with a population of 21,053 (22.5\%), followed by Kentish Plover (Charadrius alexandrinus) with a population of $20,350(21.7 \%)$. The largest area of terrain elevation at -1.0 to $-0.2 \mathrm{~m}$ was $685.4 \mathrm{ha}(38.5 \%)$ and at -0.2 to $-0.1 \mathrm{~m}$ was 320.4 ha (18.0\%). Between 2017 and 2018, the similarity in water depth classification was $47.2 \%$, reflecting climate change, a degree of water accumulation, and the wader utilization situation. A strategy for maintaining biodiversity in the Cigu salt pan wetland and conserving spoonbills is therefore proposed in this paper.
\end{abstract}

\section{Keywords}

Habitat Improvement, Movement, Platalea minor, Taiwan 


\section{Introduction}

For nearly 40 years, ecological indicators have gained increasing attention within the scientific community. Including birds, fish, and plants taxonomic groups have been used successfully to indicate environmental changes [1]. The Black-faced Spoonbill (Platalea minor, Temminck and Schlegel, 1849) is a medium-sized white water bird. In East Asia, Black-faced Spoonbills are migratory waterfowls in the winter season [2]-[7].

In 1988, only 288 birds were recorded in East Asia; however, in the winter of 2018-2019, their population increased to 4463 . The number of spoonbills in Taiwan has increased by more than 12.6-fold, from a minimum of 191 in 1991-1992 to a minimum of 2047 in 2018-2019 [7] [8] [9] [10] [11]. More than $50 \%$ of these birds winter regularly on the southwestern coast of Taiwan. However, in the spring of 2011 and 2018, synchronized censuses of Black-faced Spoonbills indicated that their population in Taiwan decreased by $446(-34.8 \%)$ and $406(-15.6 \%)$, respectively, and their population worldwide has either decreased or is stable [11]. Several researchers have suggested that factors such as climate change and habitat loss in Taiwan and the south of China may accumulate and significantly reduce the population of Black-faced Spoonbills over the next 30 years [12] [13].

The west coast of Taiwan is ecologically distinctive with sandbars, lagoons, and salt pans along its coast in the southwest. These entities have economical fishery and ecological functions and reduce flooding [14] [15]. In 2002, various habitats emerged in salt pans after salt production was stopped. However, the salt pans now support the mangroves of the lagoon and are only used for economic fishing and oyster farming, thus neglecting the growth ignoring of salt pan aquatic plants such as Ruppia maritima (Ruppiaceae), Halophila ovalis (Hydrocharitaceae), Sporobolus virginicus (Poaceae), and Sesuvium portulacastrum (Aizoaceae) and the ecological functions.

With an increasing population of Black-faced Spoonbills, food source requirements increased. However, from 2016 to 2018, the government promoted the green power policy and approved the use of 402-ha salt pans [16]. It is therefore vital to protect habitats through the introduction of ecological corridors, comprehensive and systematic management, and resource utilization and management of wetland stakeholders [17] [18].

The effects of climate change on the wintering distribution of an endangered migratory bird species have previously been investigated [18]. Numerous spatiotemporal variation studies have conducted long-term investigations and have accumulated information valuable for the geospatial analysis of foraging and habitation [19] [20]. The Cigu salt pan is one of the rehabilitated habitats of Blackfaced Spoonbills, where they and other birds use different habitats through habitat elevation, water depth, plant cover, and human activity. A part of the area contains improved habitats, making it a suitable habitat for Black-faced Spoonbills, and there is no impact on other waders. The relationship between the bird 
population and primary habitat factors has been analyzed and the results used as a reference for habitat rehabilitation and ecosystem management [21] [22]. The strategy includes maintaining wetland biodiversity and conserving Black-faced Spoonbills.

\section{Materials and Methods}

\subsection{Bird Study Area in Cigu Salt Pan in Tainan}

The Cigu salt pan, developed in 1935, was transformed into a lagoon because of land reclamation. At that time, the area was approximately 2607 ha. These low-lying lands were built with seawalls near the coast, lagoon, and river side. The production of salt during nonrainy seasons is achieved through seawater led by gates. In rainy seasons, the production of salt is stopped, and water is drained using a pumping motor. Because salt production has ceased in the Cigu salt pan, in May 2002, only a few gates were opened in winter for fishermen. Most of the remaining gates were closed, which degraded habitats. Mollusca Didontoglossa koyasensis (Scaphandridae) was the biologically dominant benthic species [22].

From October 2017 to October 2018, a bird study was conducted in the Cigu salt pan wetland, and strategies were proposed for habitat improvement and the conservation of Black-faced Spoonbills. We sampled seven sites and collected data once every 2 weeks (Figure 1). We walked along small roads and recorded all visible bird species and their respective quantities using a single-lens telescope. We analyzed variations in the population of each species and the dominant species at each site and proposed strategies to improve habitats and protect Black-faced Spoonbills.

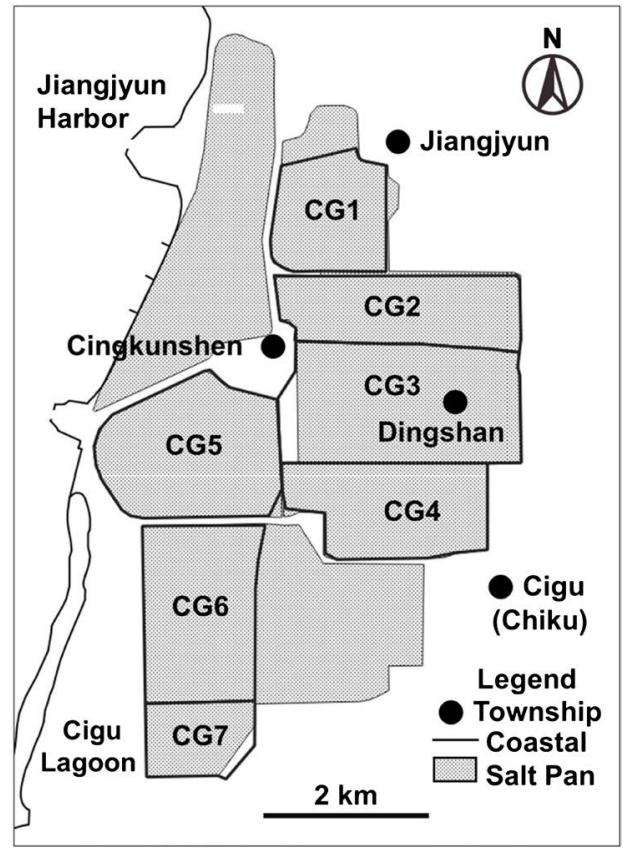

Figure 1. Cigu salt pan wetland in Tainan City. CG1 - CG7 were used as sampling sites during the water bird study. 


\subsection{Terrain Elevation and Water Depth in Cigu Salt Pan}

A digital elevation model (DEM) is an ordered array of numbers that represents the spatial distribution of elevations above an arbitrary datum in a landscape. A square-grid DEM has a matrix data structure with the topographic elevation of each pixel stored in a matrix node. The grid DEM is readily available and easy to use and has been widely employed to analyze hydrologic problems [23] [24] [25].

In this study, a terrain elevation drawing of the Cigu salt pan area in 2016 was used as a 5-m square-grid DEM [26]. We classified terrain elevation in accordance with bird habitat demand elevation as follows: -5.0 to $-1.0,-1.0$ to -0.2 , -0.2 to $-0.1,-0.1$ to $-0.05,-0.05$ to $0.0,0.0$ to $0.05,0.05$ to $0.1,0.1$ to $0.2,0.2$ to 1.0 , and 1.0 to $11(\mathrm{~m})$. Areas with different elevations were calculated using the ArcGIS Reclassify tool.

Based on images collected at the Center for Space and Remote Sensing Research, National Central University, Taiwan, we selected two satellite images obtained from satellite SPORT 7 on March 22, 2017 and SPORT 6 on March 22, 2018.

The primary purpose of this study was to estimate the impact of water depth on water birds within the study site. We used ENVI 4.8 software to classify water depths and land topography from satellite images through unsupervised classification. We defined the water depth into four classes: wet ground, $0-0.5 \mathrm{~m}, 0.5$ $1.0 \mathrm{~m}$, and deeper than $1.0 \mathrm{~m}$ [27]. Field surveys were employed to adjust and validate the classification of results.

The water birds forage in salt pans, estuary, and harvested fishponds; however, their resting area can be divided into two types: open fields with sunshine and the downwind side of clay banks, mangroves, and shrubs that blocks the chilly northern wind during a cold current [28]. Vegetation is a crucial factor in ensuring the persistence of the water bird population. Using satellite images, land vegetation was divided into four types: dense, mid-dense, moderate, and sparse [29]. Ten classes were considered for potential usage by the water birds following the addition of a dry ground, road, and building to the four types of water depth.

\subsection{Data Analysis}

We analyzed our results using the subroutine of analysis of Resemblance and Cluster of the statistical package PRIMER v.5 (PRIMER-E, Plymouth, UK) [30]. Results were considered significant when $P<0.05$. Data are presented as the mean \pm standard deviation.

\section{Results}

\subsection{Bird Communities in Cigu Salt Pan Wetland}

From October 2017 to October 2018, we conducted 24 bird surveys in the Cigu salt pan. In total, a total population of 93,614 birds of 88 species was recorded. 
The biodiversity of the total birds, the $H^{\prime}$ (loge) index was 2.67, species richness index was 5.971, and Pielou's evenness index was 0.7372, respectively. The cumulative numbers of birds were 21,053 (22.5\%), 20,350 (21.7\%), 9957 (10.6\%), 5944 (6.4\%), and 5044 (5.4\%) for Dunlin (Calidris alpina), Kentish Plover (Cha. alexandrinus), Whiskered Tern (Chlidonias hybrida), Pacific Golden Plover (Pluvialis fulva), and Red-necked Sandpiper (Ca. ruficollis), respectively. Small water birds were distributed in shallow waters and/or wet surfaces (Table 1).

Table 1. Most common birds in Cigu salt pan in Tainan City from October 27, 2017, to October 10, 2018.

\begin{tabular}{|c|c|c|c|}
\hline Family and English name & Scientific name & Cumulative number & Percentage (\%) \\
\hline \multicolumn{4}{|l|}{ Anatidae } \\
\hline Northern Pintail & Anas acuta & 2729 & 2.9 \\
\hline Eurasian Wigeon & Anas penelope & 3894 & 4.2 \\
\hline Northern Shovelers & Anas clypeata & 778 & 0.8 \\
\hline \multicolumn{4}{|l|}{ Ardeidae } \\
\hline Great Egret & Ardea alba & 2115 & 2.3 \\
\hline Little Egret & Egretta garzetta & 3355 & 3.6 \\
\hline \multicolumn{4}{|l|}{ Scolopacidae } \\
\hline Dunlin & Calidris alpine & 21,053 & 22.5 \\
\hline Red-necked Stint & Calidris ruficollis & 5044 & 5.4 \\
\hline \multicolumn{4}{|l|}{ Charadriidae } \\
\hline Kentish Plover & $\begin{array}{l}\text { Charadrius } \\
\text { alexandrinus }\end{array}$ & 20,350 & 21.7 \\
\hline Lesser Sand Plover & Charadrius mongolus & 963 & 1.0 \\
\hline Pacific Golden Plover & Pluvialis fulva & 5944 & 6.4 \\
\hline \multicolumn{4}{|l|}{ Laridae } \\
\hline Whiskered Tern & Chlidonias hybrid & 9957 & 10.6 \\
\hline Caspian Tern & Hydroprogne caspia & 2086 & 2.2 \\
\hline Little Tern & Sternula albifrons & 1026 & 1.1 \\
\hline \multicolumn{4}{|l|}{ Recurvirostridae } \\
\hline Black-winged Stilt & $\begin{array}{l}\text { Himantopus } \\
\text { himantopus }\end{array}$ & 1896 & 2.0 \\
\hline Pied Avocet & Recurvirostra avosetta & 1575 & 1.7 \\
\hline \multicolumn{4}{|l|}{ Threskiornithidae } \\
\hline Black-faced Spoonbill & Platalea minor & 1321 & 1.4 \\
\hline \multicolumn{4}{|l|}{ Passeridae } \\
\hline \multirow[t]{3}{*}{ Eurasian Tree Sparrow } & Passer montanus & 832 & 0.9 \\
\hline & Other 70 species & 8696 & 9.3 \\
\hline & Total & 93,614 & 100.0 \\
\hline
\end{tabular}


The number was concentrated in a few species, other 78 species were 8696 individual $(9.3 \%)$.

The largest number of birds recorded was 8788 on January 7, 8699 on December 10, and 8278 on December 23, respectively. The maximum number of species recorded was 51 on January 7 and 46 on both December 23 and January 21 (Figure 2). Furthermore, 3894 (4.7\%) Eurasian Wigeons (Anas penelope) were distributed in sample sites CG2, CG3, and CG5, and 1321 (1.4\%) Black-faced Spoonbills in the conservation category were distributed in the sample site CG4.

Spring, summer, autumn, and winter occurred from March 16 to April 30, May to August, September to October, and November to March 15, respectively. The group characteristics of bird emergence in winter were longer than summer by approximately 15 days (Figure 3 ). The number of birds was the highest during winter, with an average of $6723 \mathrm{birds} /$ day. The most common species of birds were as follows: Dunlin (2184), Lesser Sand Plover (Cha. mongolus) (1780), Pacific

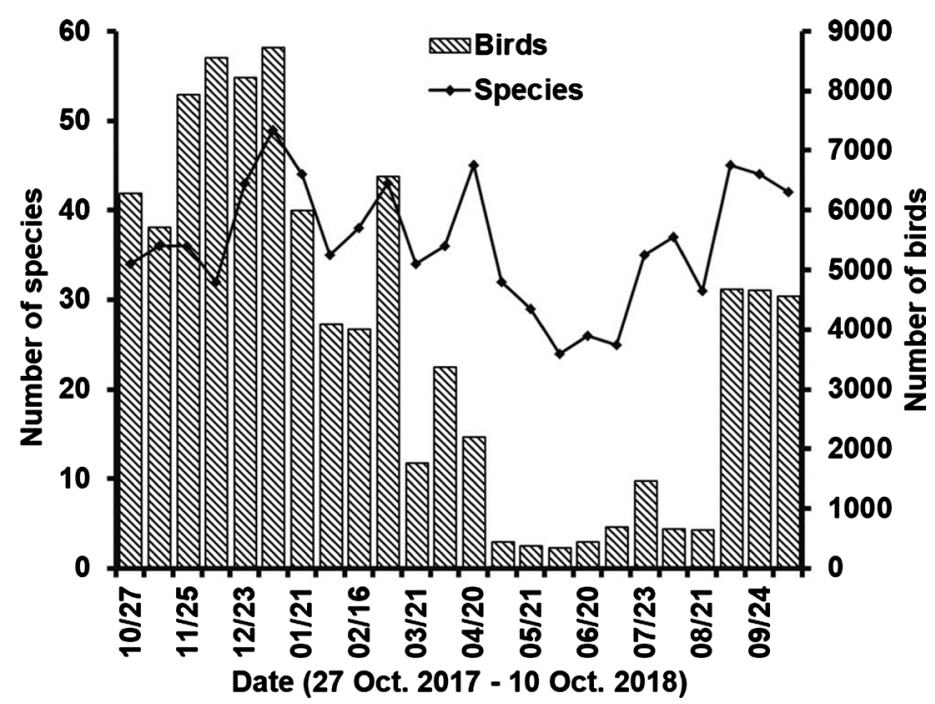

Figure 2. Variability of bird populations in the Cigu salt pan in Tainan City from October 27, 2017 to October 10, 2018.

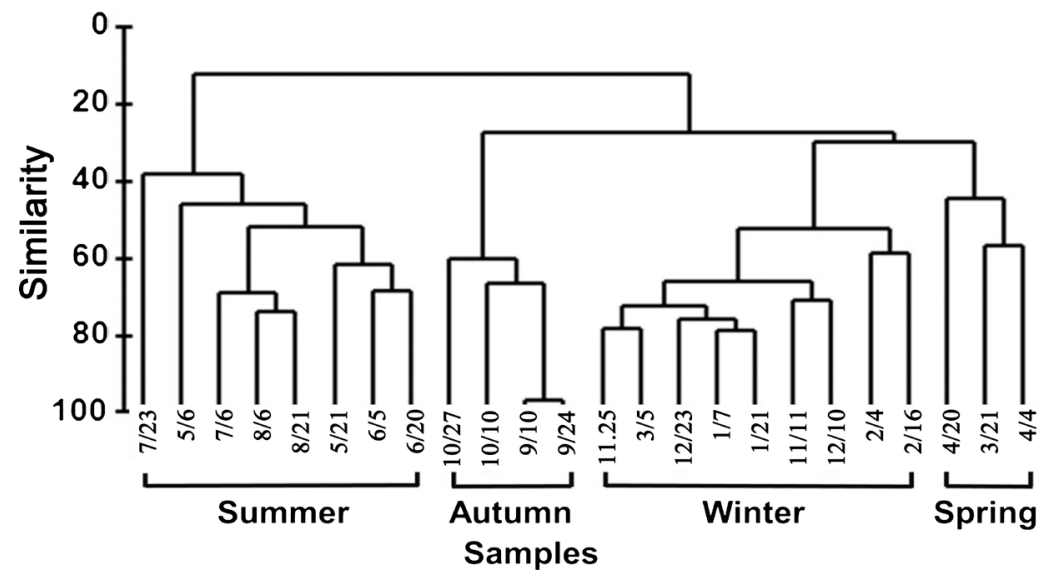

Figure 3. Season similarity in bird surveys in the Cigu salt pan in Tainan City from October 27, 2017 to October 10,2018. 
Golden Plover (440), Red-necked Stint (243), and Caspian Tern (Hydroprogne caspia) (202). An average of 5073 birds/day were observed during autumn, and the most common species were as follows: Dunlin (2128), Lesser Sand Plover (761), Black-winged Stilt (Himantopus himantopus) (321), Pied Avocet (Recurvirostra avosetta) (305), and Little Egret (Egretta garzetta) (300). An average of $2484 \mathrm{birds} /$ day were observed in spring, and the most common species were as follows: Pacific Golden Plover (463), Dunlin (499), and Lesser Sand Plover (307). The smallest number of birds was observed in summer, with an average of 669 birds/day. The main species were as follows: Little Egret (99), Little Tern (Sternula albifrons) (62), Black-winged Stilt (51), Eurasian Tree Sparrow (Passer montanus) (55), and Lesser Sand Plover (38). Although the Kentish Plover and Black-winged Stilt breeds were observed at the Cigu salt pan during spring and summer, the number of birds during winter was more than ten times that during summer, indicating that this was an important wintering habitat of small waterfowl.

For different habitats, the similarity between sample sites CG1, CG2, and CG6 was 66.9\%, primarily because the Dunlin (5961), Lesser Sand Plover (4939), Pacific Golden Plover (1573), Dunlin (1228), and Whiskered Tern (926) constituted $86.9 \%$ of the bird population; the similarity between sample sites CG3 and CG4 was 67.7\%, primarily because the Whiskered Tern (3551), Lesser Sand Plover (2377), Black-winged Stilt (611), Little Egret (835), and Dunlin (1152) constituted $80.3 \%$ of the bird population; the dissimilarity between these two groups was 58.6\%. The dissimilarity between sample areas CG5 and CG7 and the aforementioned groups were $83.1 \%, 81.4 \%, 64.0 \%$, and $59.2 \%$, respectively (Figure 4).

In addition to small birds such as Charadriidae and Scolopacidae, several wild ducks, including Northern Pinta (A. acuta), Northern Shovelers (A. clypeata), and Eurasian Wigeon, were concentrated in the sample area CG5 of the salt pan on the south side of Qingkunshen, Cigu township, which is located in the national wetland. The government should pay attention to the existing ecological status when performing ecological rehabilitation in the future. The area of the

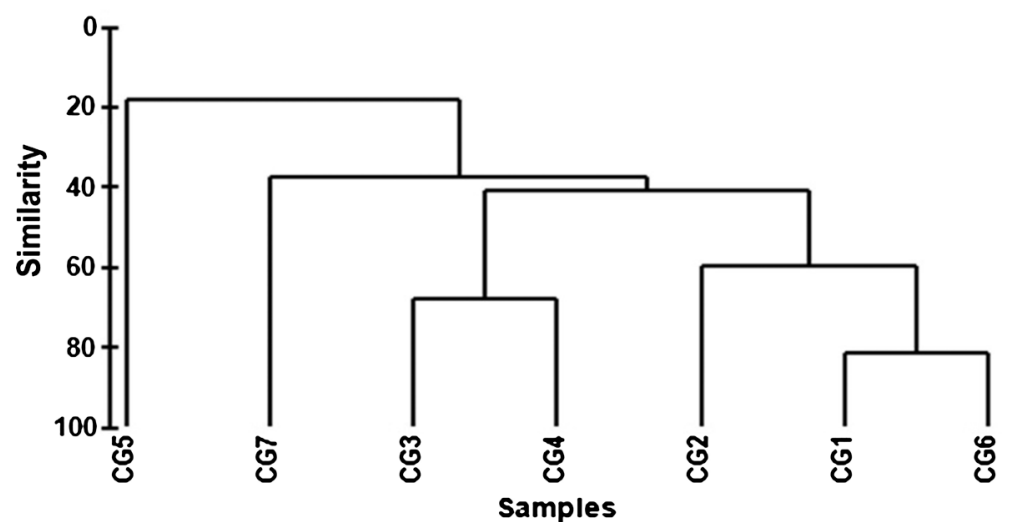

Figure 4. Site similarity of bird surveys in the Cigu salt pan in Tainan City from October 27, 2017 to October 10, 2018. 
Cigu salt pan is 2606 ha. Excluding 1482 ha, which is classified as a national wetland, 1124 ha is available as habitats and provides a small amount of ground subsistence. Natural tidal cycle planning and habitat improvement are possible.

The highest similarity was $81.2 \%$ between CG1 and CG6, whereas the lowest was $11.2 \%$ between CG1 and CG5. Based on their similarity, CG1, CG2, and CG6 were classified into group A, and intragroup similarity was $33.4 \%$. The major contributing species were Dunlin, Red-necked Stint, Kentish Plover, and Pacific Golden Plover, which accounted for $83.4 \%$ of the bird population. CG3 and CG4 were classified into group B, and intragroup similarity was $67.8 \%$. The major species in this group were Whiskered Tern, Lesser Sand Plover, Black-winged Stilt, and Little Egret, which accounted for $74.5 \%$ of the bird population (Table 2).

\subsection{Reclassification of DEM}

The area of terrain elevation of the Cigu salt pan was classified using the ArcGIS 10.3 Reclassify tool. The total area was 1779.8 ha. The size of the area where elevation ranged from approximately -1.0 to $-0.2 \mathrm{~m}$ was $685.4 \mathrm{ha}(38.5 \%)$, from -0.2 to $0.1 \mathrm{~m}$ was $320.4 \mathrm{ha}(18.0 \%)$, and from 0.2 to $1.0 \mathrm{~m}$ was 220.1 ha (12.4\%). The size of areas where elevation ranged from -0.05 to $0.0 \mathrm{~m}$ and from 0.0 to $0.05 \mathrm{~m}$ was $115.2(6.3 \%)$ and 63.8 ha (3.6\%), respectively (Figure 5).

The largest occupancy rates and terrain elevation classes were as follows: 59.7

Table 2. Dissimilarity between sample sites. Group A includes CG1, CH2, and CG6; group B includes CG3 and CG4.

\begin{tabular}{ccccccc}
\hline & A \& B & A \& CG5 & A \& CG7 & B \& CG5 & B \& CG7 & CG5 \& 7 \\
\hline Dissimilarity (\%) & 64.5 & 49.7 & 69.1 & 64.9 & 59.1 & 65.1 \\
Anas penelope & 8.0 & 8.4 & 11.1 & - & 1.2 & - \\
Anas acuta & 5.7 & 5.3 & - & - & 3.3 & - \\
Ardea alba & 2.3 & - & - & 2.2 & 4.2 & - \\
Egretta garzetta & 3.2 & - & 1.3 & 2.9 & 3.7 & - \\
Platalea minor & 4.0 & - & - & 3.3 & 6.2 & - \\
Himantopus himantopus & 3.2 & - & 1.1 & 2.6 & 3.5 & - \\
Recurvirostra avosetta & 2.0 & - & 3.6 & 1.9 & 1.2 & 3.2 \\
Pluvialis fulva & 4.9 & 7.6 & 4.2 & 9.9 & 2.1 & 11.1 \\
Charadrius mongolus & - & 4.2 & - & 3.6 & - & 4.3 \\
Charadrius mongolus & 16.7 & 16.0 & 21.3 & 7.7 & 15.1 & 19.9 \\
Calidris ruficollis & 4.0 & 5.8 & 6.2 & 4.6 & 5.7 & 2.0 \\
Calidris alpina & 15.7 & 33.2 & 19.6 & 34.0 & 6.2 & 44.7 \\
Sternula albifrons & - & - & - & 1.6 & 1.4 & - \\
Hydroprogne caspia & 1.7 & 3.4 & 2.2 & 3.4 & 1.3 & 3.4 \\
$\begin{array}{c}\text { Chlidonias hybrida } \\
\text { Cumulative percentage (\%) }\end{array}$ & 17.5 & 3.9 & 4.6 & 15.5 & 31.8 & 2.3 \\
\hline & 8.7 & 87.7 & 86.1 & 89.6 & 86.8 & 90.7 \\
\hline
\end{tabular}


ha (33.0\%) for an elevation of $0.2-1.0 \mathrm{~m}$ in CG1, 44.0 ha (18.6\%) for an elevation of $0.1-0.2 \mathrm{~m}$ in CG2, and the largest area for an elevation of -1.0 to $-0.2 \mathrm{~m}$ from CG3 to CG7. The occupancy rates of CG3, CG4, CG5, CG6, and CG7 were 136.2 (33.9\%), 104.9 (42.5\%), 200.4 (63.9\%), 179.2 (61.9\%), and 31.1 ha (28.0\%), respectively. Figure 6 displays the similarity of classification for each sample site.

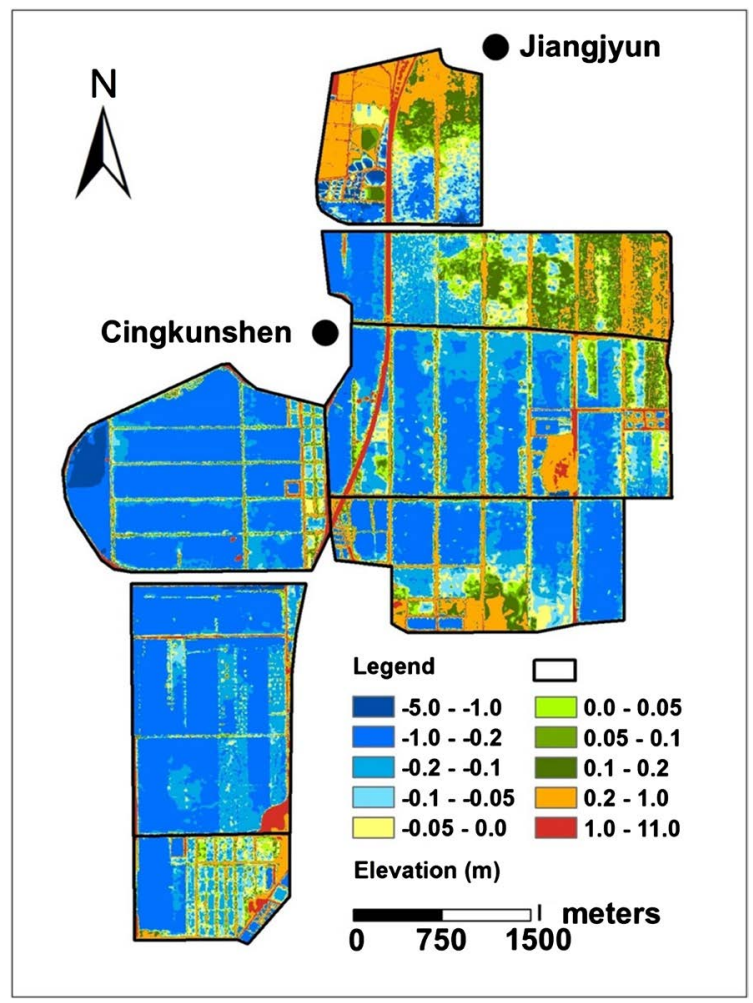

Figure 5. Classification of the terrain elevation map of the Cigu salt pan using a DEM and the ArcGIS 10.3 Reclassify tool.

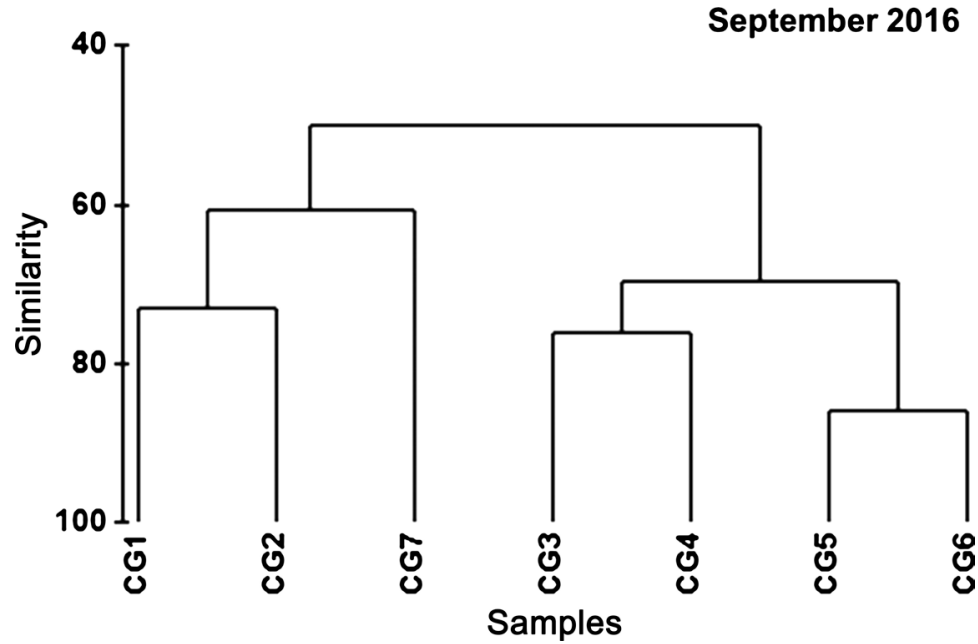

Figure 6. Similarity of elevation classification areas in each sample area of Figure 9. Classification of the terrain elevation of the Cigu salt pan using a DEM and the ArcGIS 10.3 Reclassify tool. 
In terms of group classification, CG1, CG2, and CG7 were classified into a group with an intragroup similarity of $64.6 \%$ because of the influence of the 0.2 1.0-m elevation class. CG3, CG4, CG5, and CG6 were classified into a group with an intragroup similarity of $73.3 \%$ due to the influence of the -1.0 to $-0.2-\mathrm{m}$ elevation class. The dissimilarity between the two groups was $50.0 \%$ because of the influence of elevation classes ranging from -1.0 to $-0.2 \mathrm{~m}$ and from -0.2 to $-0.1 \mathrm{~m}$, contributing $55.5 \%$ and $14.2 \%$, respectively (Figure 6).

\subsection{Classification of Water Depth}

We used ENVI 4.8 software to classify and calculate grouped areas of different water depths using Cigu salt pan data from 2017 and 2018. The total area was 1779.8 ha.

On March 22, 2017, the largest area was 455.2 ha (25.6\%), and its water depth was $0.0-0.5 \mathrm{~m}$. The second and third largest areas were 453.0 ha $(25.5 \%)$ with $0.5-1.0 \mathrm{~m}$ and 344.4 ha (19.4\%) with more than -1.0 , respectively (Figure 7 ). For each site, the largest occupancy rates of water depth classes were as follows: water depths of CG1, CG3, and CG4 were in the $0.0-0.5-\mathrm{m}$ group and accounted for 86.2 (47.8\%), $107.9(26.8 \%)$, and 93.2 ha $(37.8 \%)$, respectively. CG2 included dry soils with an area of 91.5 ha (38.7\%). CG3 and CG6 were in the 1 0.5-m group and accounted for 132.2 (32.9\%) and 156.6 ha (54.2\%), respectively. CG5 was in the group higher than $1 \mathrm{~m}$ and accounted for 255.7 ha (87.9\%). CG6 and CG7 were in the $1-0.5-\mathrm{m}$ group and accounted for areas of $175.3(60.6 \%)$

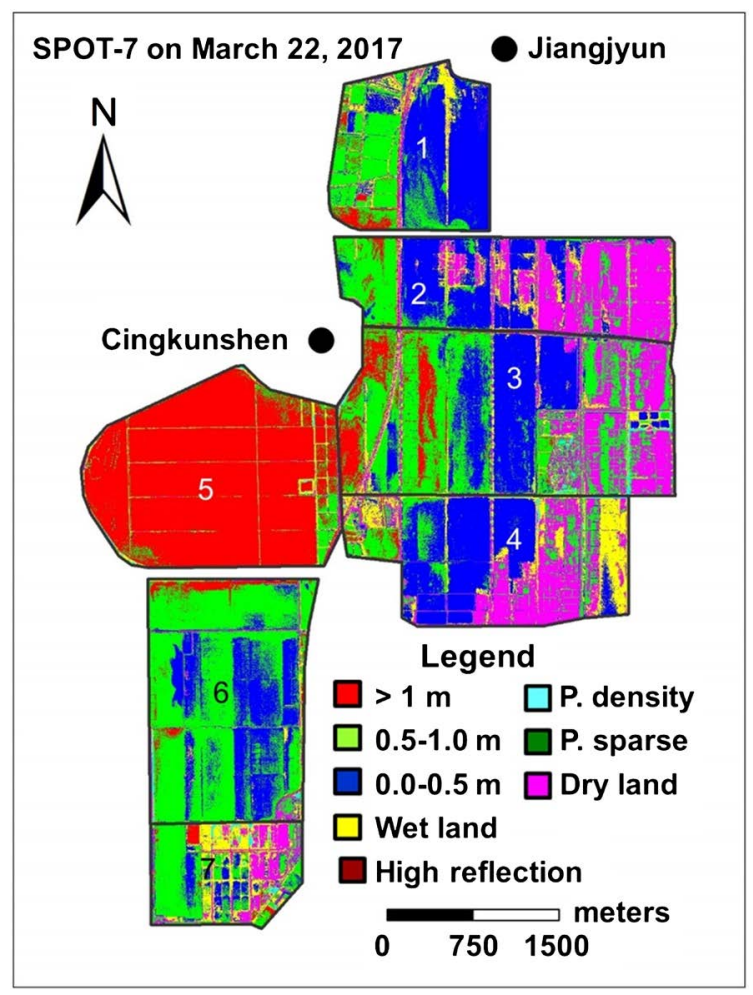

Figure 7. Classification of the water depth maps of Cigu salt pan from satellite images obtained using SPORT 7 on March 22, 2017, using ENVI 4.8 software. 
and 39.0 ha (35.0\%), respectively.

On March 22, 2017, CG1 and CG6 were classified into a group. The intragroup similarity was $69.9 \%$ due to the influence of $0.0-0.5-\mathrm{m}$ and $0.5-1.0-\mathrm{m}$ classes. CG2, CG3, and CG4 were also classified into a group. The intragroup similarity was $72.6 \%$ because of the influence of the $1.0-0.5-\mathrm{m}$ group and dry land classes. The dissimilarity between these two groups was $41.0 \%$ because of the influence of the $0.5-1.0-\mathrm{m}$ group (35.1\%) and dry land group (33.0\%). The dissimilarity between CG5 and the two forward groups was $83.3 \%$ and $84.1 \%$ due to the influence of the class with an elevation higher than $1 \mathrm{~m}$ (Figure 8).

On March 22, 2018, the largest occupancy rate of water depth classes was 0.0 $0.5 \mathrm{~m}$ covering an area of $501.1 \mathrm{ha}(28.8 \%)$. The second largest area was 454.3 ha (25.5\%) with 0.5 - 1.0-m elevation, and the third largest area was 334.6 ha $(18.8 \%)$ with an elevation of $\geq 1.0 \mathrm{~m}$. For each site, the largest occupancy rates of water depth classes were as follows: CG1, CG2, and CG4 in the $0.5-0.0-\mathrm{m}$ elevation group accounting for 93.9 (52.0\%), 123.7 (52.3\%), and 96.3 ha, respectively. CG3 and CG6 in the $1-0.5$-m elevation group accounting for 132.2 (32.9\%) and 156.6 ha (54.2\%), respectively. CG5 was in a group with an elevation of $\geq 1 \mathrm{~m}$ and accounted for 253.7 ha (80.9\%). CG7 was a dry land group accounting for 27.6 ha (24.8\%) (Figure 9).

On March 22, 2018, CG1, CG2, and CG4 were classified into a group with intragroup similarity accounting for $82.2 \%$ because of the influence of the 0.0 0.5 -m elevation class. CG3 and CG6 were classified into a group with intragroup similarity accounting for $76.6 \%$ due to the influence of the $0.5-1.0-\mathrm{m}$ elevation class. The dissimilarity between the two groups was $38.4 \%$ because of the influence of $0.5-1.0-\mathrm{m}$ and $0.0-0.5-\mathrm{m}$ elevation classes (51.0\% and $14.3 \%)$, respectively. The dissimilarity between CG5 and forward two groups were $77.8 \%$ and $73.9 \%$, respectively, due to the influence of an elevation of $1 \mathrm{~m}$ or more (Figure 10).

The area similarity in water depth classification between 2017 and 2018 was $47.3 \%$ and $52.0 \%$, respectively, because of the influence of the $0.0-0.5-\mathrm{m}$ elevation class. The dissimilarity between the two years was $47.2 \%$ due to the influence of

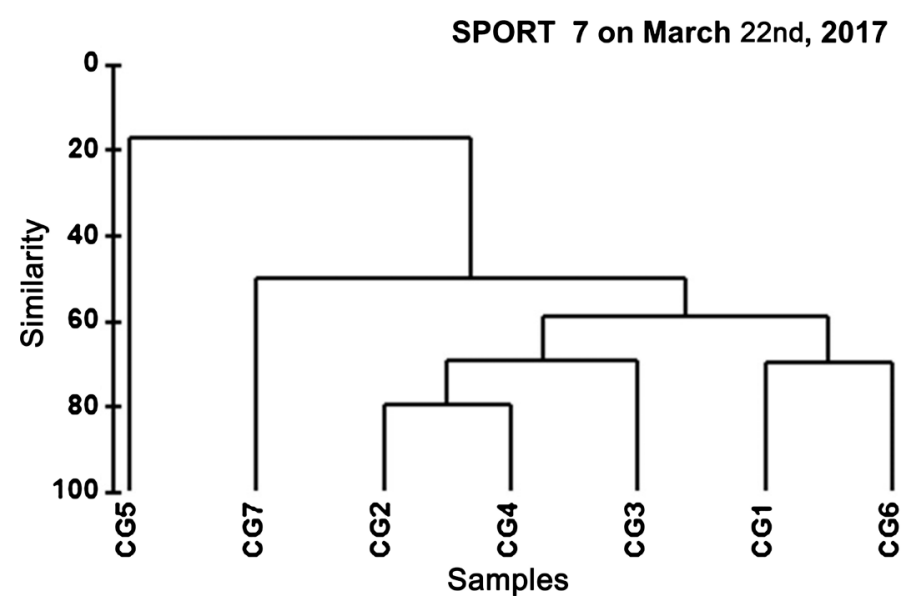

Figure 8. Similarity of water depth classification areas in each sample area of the Cigu salt pan in March 22, 2017. 


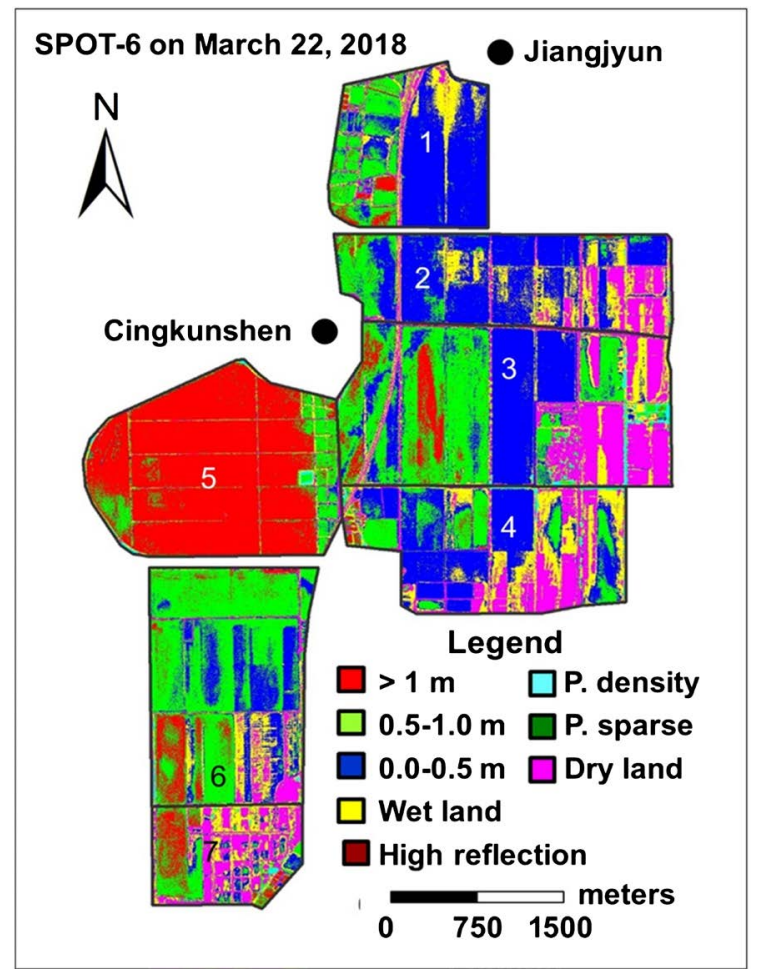

Figure 9. Classification of water depth maps of the Cigu salt pan from satellite images obtained from SPORT 6 on March 22, 2018, using ENVI 4.8 software.

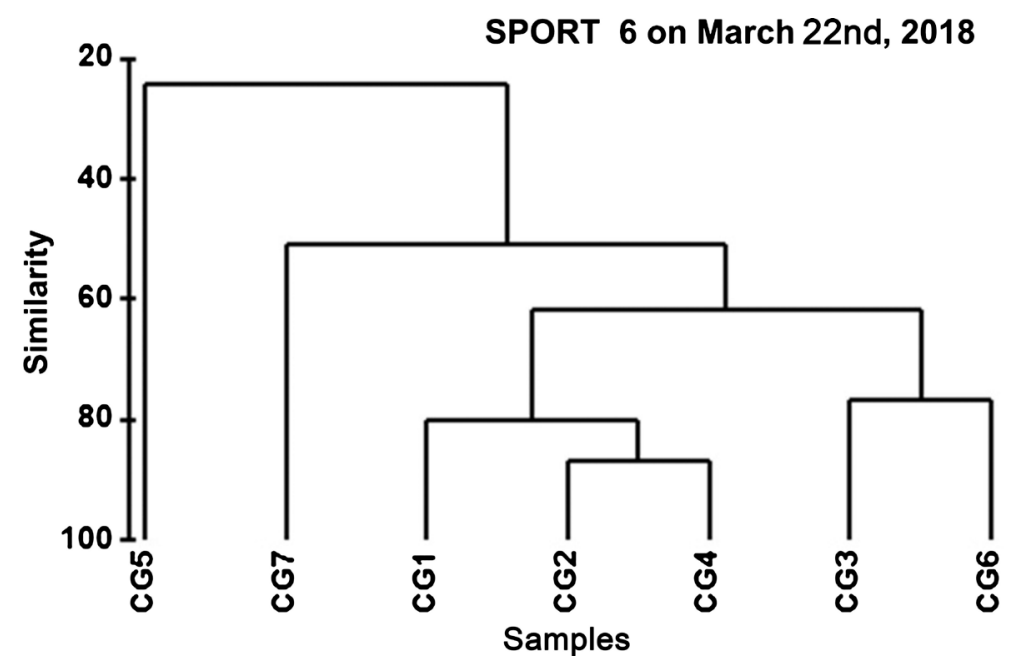

Figure 10. Similarity of water depth classification areas in each sample area of the Cigu salt pan on March 22, 2018.

elevation of more than or equal to $1 \mathrm{~m}(28.0 \%)$ and $0.5-1.0 \mathrm{~m}(21.9 \%)$.

\section{Discussion}

Previous and recent research on the Budai salt pan wetland has indicated that the Black-faced Spoonbill migrates to Taiwan to consume large amounts of coarse fish after harvesting in early winter [18]. In late winter, coarse fishes are reduced, and they move to estuary and intertidal zones to forage. The mullets on 
the southwest coast of Taiwan start to breed after autumn, and juveniles grow to maturity on the coastal wetlands [9] [31]. If Cigu salt pan habitats were improved and more juveniles were introduced, this could steadily increase the number of Black-faced Spoonbills [32].

The Group investigations of Black-faced Spoonbills in the Cigu salt pan revealed that they were mostly concentrated in CG4. To protect this endangered species, an ecological corridor should be established on the southwestern coast and estuary of Taiwan. This will involve designating a series of sites as wildlife refuges, major wildlife habitats, nationally important wetlands, and biological protection lands, especially areas that have not been designated as national wetlands. However, in December 2016, the government started to promote Chiayi and Tainan salt pan areas as a solar photovoltaic base [16]. By the end of 2018, 202 ha in the Budai salt pan and 214 ha in the Cigu salt pan were established as a base for solar photovoltaic equipment. This is expected to have a serious effect on water birds [16].

In 2017 and 2018, most of the Anatidae, such as Eurasian Wigeon, Northern Shoveler, and Northern Pintail, were concentrated in CG5 where water levels were deep. Small size species such as Charadriidae and Scolopacidae were concentrated in sample sites CG1, CG2, and CG6 where water levels were low (Figure 7 and Figure 9). Depending on the environmental conditions of the salt pan habitats, suitable water depths, and distribution of food sources, the birds can move flexibly to feed, rest, or seek refuge in these areas [16]. Therefore, in accordance with relevant laws, the salt pans were designated as ecological conservation areas. In future ecological restoration, the existing ecological status of an area should be noted. The bird survey section of the Cigu salt pan wetland revealed that the top ten most abundant birds consisted of two species of Anatidae, two species of Ardeidae, two species of Charadriidae, two species of Laridae, and two species of Scolopacidae. This indicated that different water depths create habitat diversity.

We suggest that the government should consider the finance and implementation of current conservation plans for the Cigu salt pan wetland. Regarding salt pans that have not been designated as wetlands (about $700 \mathrm{ha}$ ), it has been recommended that local governments conduct public land appropriation for the rehabilitation of biodiversity habitats [33] [34]. Furthermore, local governments (based on local conditions) should designate some areas for natural ecology-mimicking mangroves or farmed fish. This will create more employment opportunities in the local community as well as increase and decentralize food sources for the birds. Following successful rehabilitation, these salt pans should be designated important wetland areas to expand the wetland and improve outcomes. We observed that Dunlin, Red-necked Stint, Lesser Sand Plover, Whiskered Tern, and Whiskered Tern foraged in the intertidal zones, lagoons, and surimi areas and then returned to salt pans to rest.

According to Article 22 of the Wetland Conservation Act (2013), the land lo- 
cated within the scope of important wetlands may be levied, allocated, or leased in accordance with the law to implement the conservation and utilization plan [35].

To implement the Wetland of Importance Conservation and Utilization Plan, competent government authorities may, if deemed necessary, expropriate, allocate, or lease the land situated within important wetlands in accordance with legal requirements.

For public land that has not been designated an important wetland area, we suggest that the Tainan government should conduct public land appropriation for the rehabilitation of biodiversity habitats.

\section{Wetland Management}

Wetland management includes internal and external factors of the national wetland of the Cigu salt pan. First, within the wetlands, the management office of the Taijiang National Park handles, manages, reviews and disposes wetland plans. Major activities in relation to finance and implementation plans for the Cigu salt pan wetland include 1) a wetland ecological resource survey, 2) ecological rehabilitation in the rehabilitated area, 3) piling setting and cadastral segmentation and measurement, 4) sampling and testing of wetland water quality, and 5) establishing community participation platforms to maintain a stable ecosystem that will promote sustainable development of the overall environment. Only a small land subsidy is available for the Cigu salt pan.

Second, it is recommended that the Tainan government should conduct public land appropriation of the abandoned salt pans outside the wetland area for the rehabilitation of biodiversity habitats [36]. Suitable sites should be selected and a sluice-gateway constructed for tidal waves following detailed investigation and evaluation. Several areas could be designated for natural ecology-mimicking mangrove nature parks or fish farming. The government could then hire local fishermen to participate in shallow-scale farming and patrolling; the income from farming could be used as a fund for wetland rehabilitation. This will also provide employment opportunities for local communities. The Mangrove Nature Park can provide commercial value through ecotourism and environmental education and bestow a sense of identity and honor on the community. Following the harvest, the coarse fish that live in the farmed ponds can be an excellent source of bird food. The main purpose of these abandoned salt pans is to create habitats of the highest quality to attract these birds [37] [38] [39].

The imminent threat of climate change is causing a biodiversity crisis; thus, rehabilitating habitats in southwestern Taiwan is an urgent need. With regard to the ecological capacity of the wetland, we suggest that wetland resources should be wisely used in an inclusive manner to maintain their stability with regard to both quality and quantity, and that biological resources should be used judiciously; this means ensuring timely, fitting, moderate, and adequate sustainable utilization of the water, land, and biological resources. 
Korean tidal wetlands are crucial for the habitats of economic fish and migratory birds. Different forms of tidal utilization affect management strategies [40]. Such a framework can be applied to other species and used as a reference habitat; corridor planning and shelter design for the conservation of wetlands in gap areas could improve habitat conditions and connectivity [28] [41] [42]. The same strategy may therefore yield similar results for gaps in sample sites CG2 and CG4 in the Cigu salt pan.

Black-faced Spoonbill and other water birds are maneuvering to move for food and stop habitat in each salt field according to the environmental conditions, appropriate water depth, and food distribution of each salt field habitat [43] [44] [45]. Protecting habitats is the best method to protect these birds. Therefore, according to relevant laws and regulations, the salt field is designated as an ecological protection land, or a water gate is set to adjust the water level and improve the habitat quality. It is a direct and effective method.

\section{Acknowledgements}

The study on the reclassification of a DEM was supported by National Cheng Kung University, Taiwan. This manuscript was edited by Wallace Academic Editing.

\section{Conflicts of Interest}

The authors declare no conflicts of interest regarding the publication of this paper.

\section{References}

[1] Smith-Cartwright, K.A. and Chow-Frase, P. (2011) Application of the Index of Marsh Bird Community Integrity to Coastal Wetlands of Georgian Bay and Lake Ontario, Canada. Ecological Indicators, 11, 1482-1486.

https://doi.org/10.1016/j.ecolind.2011.03.006

[2] Hancock, J.A., Kushlan, J.A. and Kahl, M.P. (1992) Storks, Ibises and Spoonbills of the World. Academic Press, London.

[3] Ueng, Y.-T. and Kuo, C.-C. (1992) The Report of Black-Faced Spoonbill Staying on the North Side of Tsenwen River, Taiwan, ROC. From August 1991 to May 1992. Wild Birds, 1992, 59-68.

[4] Wang, S. (1998) China Red Data Book of Endangered Animals. Science Press, Beijing.

[5] Ueta, M. and Higuchi, H. (2002) Difference in Migration Pattern between Adult and Immature Birds Using Satellites. Auk, 119, 832-835. https://doi.org/10.1642/0004-8038(2002)119[0832:DIMPBA]2.0.CO;2

[6] Ueng, Y.-T., Wang, J.-P. and Hou, P.-C.L. (2007) Predicting Population Trends of the Black-Faced Spoonbill (Platalea minor). The Wilson Journal of Ornithology, 119, 246-252. https://doi.org/10.1676/05-112.1

[7] Kennerley, P.R. (1990) A Review of the Status and Distribution of the Black-Faced Spoonbill. Hong Kong Bird Report, 1989, 116-125.

[8] Sung, Y.-H., Tse, I.W.-L. and Yu, Y.-T. (2018) Population Trends of the 
Black-Faced Poonbill Platalea minor. Analysis of Data from International Synchronized Censuses. Bird Conservation International, 28, 157-167. https://doi.org/10.1017/S0959270917000016

[9] Ueng, Y.-T. (2007) Population Biology of the Black-Faced Spoonbill Wintering in Southwestern Taiwan. Dissertation for Doctor of Philosophy, Department of Life Sciences, National Cheng Kung University, Tainan.

[10] Forestry Bureau (2018) 2018 Black-Faced Spoonbill Global Census Results. https://www.forest.gov.tw/forest-news/0062156

[11] Forestry Bureau (2019) 2019 Black-Faced Spoonbill Global Census Results. https://www.eaaflyway.net/2019-international-black-faced-spoonbill-census-results

[12] Xia, S., Yua, X., Millington, S., Liu, Y., Jia, Y., Wang, L., Hou, X. and Jiang, L. (2017) Identifying Priority Sites and Gaps for the Conservation of Migratory Waterbirds in China's Coastal Wetlands. Biological Conservation, 210, 72-82. https://doi.org/10.1016/j.biocon.2016.07.025

[13] Pickett, E.J., Chan, M., Chang, W.A., Llcock, J., Chan, S., Hu, J., Lee, K., Smith, B., Xing, S., Yu, Y.-T. and Bonebrakem, T.C. (2018) Cryptic and Cumulative Impacts on the Wintering Habitat of the Endangered Black-Faced Spoonbill (Platalea minor) Risk Its Long-Term Viability. Environmental Conservation, 45, 147-152. https://doi.org/10.1017/S0376892917000340

[14] Hsieh, H.-L., Chen, C.-P. and Linm, Y.-Y. (2004) Strategic Planning for a Wetlands Conservation Greenway along the West Coast of Taiwan. Ocean \& Coastal Management, 47, 257-272. https://doi.org/10.1016/j.ocecoaman.2004.01.005

[15] Yang, J.Y.-C. and Ueng, Y.-T. (2011) Taiwan's Wetlands of Importance. Urban and Rural Development Branch, Construction and Planning Agency, Ministry of the Interior, Taipei.

[16] Ueng, Y.-T., Chiu, T.-C., Deng, P.-L. and Liu, C.-L. (2017) The Conflict of Solar Nergy Development versus Black-Faced Spoonbill's Habitat Preservation in Budai Salt Pans, Chiayi. Journal Wetlands, 6, 19-31.

[17] Chen, H., Chang, Y.-C. and Chen, K.-C. (2014) Integrated Wetland Management: An Analysis with Group Model Building Based on System Dynamics Model. Journal of Environmental Management, 46, 309-319. https://doi.org/10.1016/j.jenvman.2014.05.038

[18] Hu, J., Hu, H. and Jiang, Z. (2016) The Impacts of Climate Change on the Wintering Distribution of an Endangered Migratory Bird. Oecologia, 164, 555-565. https://doi.org/10.1007/s00442-010-1732-Z

[19] Chen, P.-S., Chyi, S.-J., Kuo, T.H., Deng, P.-L., Liu, C.-L. and Ueng, Y.-T. (2018) Environmental Carrying Capacity and Conservation Strategy for the Black-Faced Spoonbill (Platalea minor) on the Southwest Coast of Taiwan. 2018 International Wetland Conference, Taipei, 21 November 2018, 6-8.

[20] Bouwhuis, S. (2018) Special Feature: Linking Organismal Functions, Life History Strategies and Population Performance. Journal of Animal Ecology, 87, 891-892. https://doi.org/10.1111/1365-2656.12836

[21] Tian, B., Zhou, Y., Zhang, L. and Yuan, L. (2008) Analyzing the Habitat Suitability for Migratory Birds at the Chongming Dongtan Nature Reserve in Shanghai, China. Estuarine, Coastal and Shelf Science, 80, 296-302. https://doi.org/10.1016/j.ecss.2008.08.014

[22] Li, W.-H. (2010) The Ecological Quality Assessment of the Unattended Salt Pans in Coastal of Southwestern Taiwan. Thesis of Master, Department of Environmental Engineering Kun Shan University, Tainan. 
[23] Moore, I.D., Grayson, R.B. and Ladson, A.R. (1991) Digital Terrain Modelling: A Review of Hydrological, Geomorphological, and Biological Applications. Hydrological Processes, 5, 3-30. https://doi.org/10.1002/hyp.3360050103

[24] Tarboton, D.G. (1997) A New Method for the Determination of Flow Directions and Upslope Areas in Grid Digital Elevation Models. Water Resources Research, 33, 309-319. https://doi.org/10.1029/96WR03137

[25] Bates, E.M., Koczur, L.M., Krainyk, A., Ballard, B.M. and Kasner, A.C. (2016) Spatial and Temporal Dynamics of Foraging Habitat Availability for Reddish Egrets in the Laguna Madre, Texas. International Journal of Biodiversity and Conservation, $\mathbf{8}$, 251-258. https://doi.org/10.5897/IJBC2016.1025

[26] Real World Engineering Consultants Inc. (2017) Cigu Salt Pan Wetland Numerical Topographic Survey Results. Construction and Planning Agency, Taipei.

[27] Chen, K.-N. (2014) Spatiotemporal Dynamics of Ecological Variation Affect an Endangered Migratory Bird Black-Faced Spoonbill (Platalea minor) in Southwestern Coast of Taiwan. Open Journal of Ecology, 4, 87-97. https://doi.org/10.4236/oje.2014.43011

[28] Chen, K.-N., Fang, Y.-H., Lien, Y.-H. and Ueng, Y.-T. (2015) Eating Patterns of Kentish Plover during Wintering at Zengwun Estuary in Southwestern Taiwan. Journal Wetlands, 4, 57-64.

[29] Lee, T.-M. and Yeh, H.-C. (2009) Applying Remote Sensing Techniques to Monitor Shifting Wetland Vegetation: A Case Study of Danshui River Estuary Mangrove Communities, Taiwan. Ecological Engineering, 35, 487-496. https://doi.org/10.1016/j.ecoleng.2008.01.007

[30] Krebs, C.J. (1999) Ecological Methodology. 2nd Edition, Benjamin/Cummings, Menlo Park.

[31] Wang, Y. (2015) The Ecological Study and Habitat Management of the Black Faced Spoonbill in Taijiang National Park.

[32] Chen, M.-J. (2012) The Composition of Fry and Engraulid Breeding Season in the Chiku Wetland of Taiwan. Thesis of Master, Department of Environmental Engineering Kun Shan University, Tainan.

[33] Ministry of the Interior (2017) Handbook of the Public Land Appropriation. http://eb1.hcc.edu.tw/edu/data/edudoc/201710251635060.pdf

[34] Ministry of Finance (2018) National Property Act. https://law.moj.gov.tw/ENG/LawClass/LawAll.aspx?pcode=G0370001

[35] Ministry of the Interior (2013) Wetland Conservation Act. https://law.moj.gov.tw/ENG/LawClass/LawAll.aspx?pcode=D0070209

[36] Aljerf, L. (2017) Biodiversity Is Key for More Variety for Better Society. Biodiversity International Journal, 1, 4-7. https://doi.org/10.15406/bij.2017.01.00002

[37] Mellink, E. and Riojas-López, M.E. (2018) The Demise of a Tropical Coastal Lagoon as Breeding Habitat for Ground-Nesting Waterbirds: Unintended, But Anticipated Consequences of Development. Coastal Management, 45, 253-269. https://doi.org/10.1080/08920753.2017.1303766

[38] Mellink, E., Luévano, J. and Riojas-López, M.E. (2018) Half a Century of Changes in Waterbird Populations in a Semiarid Wetland System. Wetlands Ecology and Management, 26, 1047-1060. https://doi.org/10.1007/s11273-018-9630-y

[39] Duarte, A., Hatfield, J.S., Swannack, T.M., Forstner, M.R.J., Green, M.C. and Weckerly, F.W. (2016) Simulating Range-Wide Population and Breeding Habitat Dynamics for an Endangered Woodland Warbler in the Face of Uncertainty. Ecologi- 
cal Modelling, 320, 52-61. https://doi.org/10.1016/j.ecolmodel.2015.09.018

[40] Hong, S.-R., Koh, C.-H., Harris, R.R., Kim, J.-E., Lee, J.-S. and Ihm, B.-S. (2010) Korean Tidal Wetlands Are Particularly Important as Nurseries for Economically Important Fishes and Habitats for Migratory Birds. Environmental Management, 45, 1014-1026. https://doi.org/10.1007/s00267-006-0164-3

[41] Chen, T.-S., Lin, H.-J. and Huang, S.-Y. (2015) A Framework on Habitat Connectivity among Taiwan's Wetlands for Overwintering Black-Faced Spoonbill. Ocean \& Coastal Management, 116, 78-88. https://doi.org/10.1016/j.ocecoaman.2015.07.002

[42] Lin, A.-C., Lin, H.-J. and Huang, W.-B. (2018) Restoration Plan of Chiku Pan. The 9 th Conference on Taiwan Wetland Ecosystems, Taipei, 5 May 2018, 61.

[43] Swennen, C. and Yu, Y.-T. (2004) Notes on Feeding Structures of the Black-Faced Spoonbill Platalea minor. Ornithological Science, 3, 119-124.

https://doi.org/10.2326/osj.3.119

[44] Swennen, C. and Yu, Y.-T. (2005) Food and Feeding Behavior of the Black-Faced Spoonbill. Waterbirds, 28, 19-27. https://doi.org/10.1675/1524-4695(2005)028[0019:FAFBOT]2.0.CO;2

[45] Ueng, Y.-T., Perng, J.-J., Wang, J.-P., Weng, J.-H. and Hou, P.-C.L. (2007) Diet of the Black-Faced Spoonbill Wintering at Chiku Wetland in Southwestern Taiwan. Waterbirds, 30, 86-91. https://doi.org/10.1675/1524-4695(2007)030[0086:DOTBSW]2.0.CO;2 